\title{
The Effect of Tightening on the Corrosion Properties of the PVD Layers on Magnesium AZ91D Alloy
}

\author{
Janusz Kaminski*, Michał Tacikowski, Agnieszka Brojanowska, Beata Kucharska, \\ Tadeusz Wierzchon \\ Faculty of Materials Science and Engineering, Warsaw University of Technology, Warsaw, Poland \\ Email: ${ }^{* j k a m i n s k i @ m e i l . p w . e d u . p l ~}$
}

Received 18 June 2014; revised 16 July 2014; accepted 7 August 2014

Copyright (C) 2014 by authors and Scientific Research Publishing Inc.

This work is licensed under the Creative Commons Attribution International License (CC BY).

http://creativecommons.org/licenses/by/4.0/

(c) (i) 0 pen Access

\begin{abstract}
The corrosive properties of PVD TiN-Ti-Al type composite titanium nitride layer with titanium and aluminium sub-layers system on the AZ91D magnesium alloy and its sub-layers were investigated by using polarization method and impedance spectroscopy, specifically, in terms of the hydrothermal tightening effect. The aim was to explain the mechanisms which contribute to high anticorrosive properties obtained by hydrothermal tightening. It was stated that the hydrothermal treatment changes the surface topography of the examined layers, most probably due to the formation of a continuous titanium oxides film. Tightening significantly modifies the corrosion resistance of the particular component sub-layers of the TiN-Ti-Al layer which exhibits optimum electrochemical parameters. It was shown that the increase of the electrochemical parameters is controlled by tightening of the outside titanium nitride layer, whereas the aluminium sub-layer plays a critical role in creating proper conditions for the hydrothermal tightening of titanium nitride.
\end{abstract}

\section{Keywords}

Magnesium Alloys, Titanium Nitride, PVD Layers, Tightening, Corrosion Resistance

\section{Introduction}

A number of favourable properties, especially low density ones, characterise magnesium alloys and this increases their suitability to various different applications. However, high electrochemical activity of magnesium significantly limits possibilities in their applications in various environments. Therefore, there has been a broad

*Corresponding author.

How to cite this paper: Kaminski, J., Tacikowski, M., Brojanowska, A., Kucharska, B. and Wierzchon, T. (2014) The Effect of Tightening on the Corrosion Properties of the PVD Layers on Magnesium AZ91D Alloy. Journal of Surface Engineered Materials and Advanced Technology, 4, 270-281. http://dx.doi.org/10.4236/jsemat.2014.45031 
research conducted in order to find new ways of improving corrosion resistance of magnesium alloys, mainly with a use of the surface engineering methods [1]. Producing on the magnesium alloys, TiN-Ti-Al type anticorrosive, composite titanium nitride layers on a titanium and aluminium sub-layer (TiN2Ti1Al10) seems to be one of the prospective solutions [2]. In order to produce thin metallic coatings (up to $10 \mu \mathrm{m}$ )—aluminium, chromium, titanium and their nitrides on the magnesium alloys, PVD methods are usually applied, in particular, magnetron sputtering and arc evaporation [1]-[10]. These methods enable precise control of the thickness of deposited coatings $(+/-0.1 \mu \mathrm{m})$ and ensure a high quality surface and relatively little roughness in comparison to the coatings produced by using anode oxidation methods, which is important due to both their corrosion and tribological properties [11]. With the use of PVD methods, the main disadvantage of the coatings produced, is their limited tightness determined by their specific structure. It results from structural defects which occur in the form of droplets, craters and pinholes during the deposition process and are typical of PVD methods. Such defects are the source of discontinuity in the coatings and, if they run across the layer, they open the way for corrosion environment contact with the substrate and therefore lead to the formation of corrosion cells between a layer and the substrate. This results in an accelerated galvanic corrosion [12]. The cathodic nature of the conductive coatings on magnesium alloys (including chromium and titanium nitrides) and structure defects and high potential difference between a coating and a very active substrate (magnesium alloy) are locally favourable to very intensive corrosion processes. For this reason, tightening of the coatings is crucial for ensuring corrosion resistance of treated magnesium alloy protected with a coating. Hence, there have been different solutions which were proposed in order to increase coatings tightness [8]-[12], some have been more effective than others. So far, hybrid treatment developed by Hoche et al. [11] seems the most efficient. It consists in creating a multilayer composite structure in which the activity of the outer layer of titanium nitride was decreased by magnesium doping and through isolating it from the previously plasma oxidised substrate by a multilayer structure consisting of $\mathrm{Al}-\mathrm{Al}_{2} \mathrm{O}_{3}$ arranged alternately. Such solution, as demonstrated by the authors are very efficient in terms of anticorrosion but may ensure only limited friction resistance [11]. Exceptionally high corrosion resistance of the TiN2Ti1Al10 composite layer produced with PVD methods may be obtained through the newly developed hybrid treatment. The final tightening treatment conducted with a hydrothermal method which has not yet been used with regard to the nitride coatings. Is the crucial element of that process.

This treatment, applied to TiN2Ti1Al10 layer, results in a significantly high corrosion potential shift towards the anode side. This comes close to the level characteristic for titanium nitride $\left(E_{\text {cor }}=-250 \mathrm{mV}\right)$ [13].

It is essential from a cognitive perspective to describe a mechanism of the increase of anticorrosion properties caused by the tightening treatment conducted with hydrothermal method. It is also important in terms of determining the ways of optimising filling treatment. In particular, the role of the sub-layers in obtaining the final effect of such significant improvement in corrosion resistance should be experimentally verified. The question which seems important to be answered is, within which of the sub-layers of a composite layer, the hydrothermal tightening takes place (according to the initial assumption such role was assigned to the aluminium sub-layer). Therefore, the subject of this paper was to conduct a detailed analysis of the correlation between the layers microstructure, corrosion processes occurring on the sub-layers which constitute the TiN2Ti1Al10 composite titanium nitride layer, and the effect of the tightening treatment on them.

\section{Experimental Methods}

Surface composite titanium nitride layers $(2 \mu \mathrm{m})$ with a titanium $(1 \mu \mathrm{m})$ and aluminium $(7 \mu \mathrm{m})$ sub-layer with a thickness of $10 \mu \mathrm{m}$ (TiN2Ti1Al10) were produced with PVD methods on the AZ91D type alloy (9 wt\% Al, 0.7 wt.\% Zn). The layers were produced with the use of a hybrid method (Figure 1) in which the intermediate aluminium coating was first deposited on the AZ91D alloy, followed by the titanium transition coating deposition with the use of a magnetron sputtering method. Finally, the surface titanium nitride coating of TiN type was produced by an arc evaporation method.

The AZ91D alloy substrate previously subjected to mechanical polishing, and ultrasonic rinsing were prepared to the intermediate aluminum coating deposition process by about 5 min ion etching with argon ions. The same ion etching procedure preceded the subsequent stage of deposition of the titanium transition coating. Prior to the outside titanium nitride coating deposition, the 5 min etching was performed using the titanium ions the arc source. The outside nitride coating deposition was performed in reactive arc evaporation process using titanium source and nitrogen atmosphere. The etching and deposition conditions were given in Table 1 . The final 


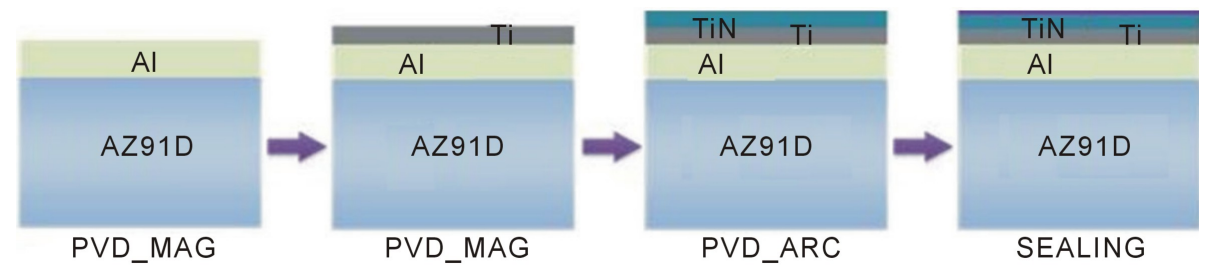

Figure 1. A scheme of hybrid technology of producing diffusive composite layers of titanium nitride with an intermediate TiN2Ti1Al10 type aluminium coating; (PVD MAG-magnetron sputtering, PVD ARC — arc evaporating, SEALING — tightening by hydrothermal method).

Table 1. The PVD processes parameters.

\begin{tabular}{cccccc}
\hline \multirow{2}{*}{ PARAMETER } & \multicolumn{2}{c}{ ION ETCHING } & \multicolumn{3}{c}{ DEPOSITION } \\
\cline { 3 - 6 } SOURCE & $\begin{array}{c}\text { Arc source, } \\
\text { titanium cathode }\end{array}$ & $\begin{array}{c}\text { Magnetron, } \\
\text { argon }\end{array}$ & $\begin{array}{c}\text { Magnetron, alumi- } \\
\text { num cathode }\end{array}$ & $\begin{array}{c}\text { Magnetron, titanium } \\
\text { cathode }\end{array}$ & $\begin{array}{c}\text { Arc source, titanium } \\
\text { cathode, nitrogen }\end{array}$ \\
\hline $\begin{array}{c}\text { CURRENT } \\
\text { BIAS }\end{array}$ & $50 \mathrm{~A}$ & $5 \mathrm{~A}$ & $5 \mathrm{~A}$ & $5 \mathrm{~A}$ & $50 \mathrm{~A}$ \\
SUBSTRATE & $600 \mathrm{~V}$ & $800 \mathrm{~V}$ & $100 \mathrm{~V}$ & $100 \mathrm{~V}$ & $100 \mathrm{~V} / 10 \mathrm{KHZ}$ \\
TEMPERATURE & CA. $200^{\circ} \mathrm{C}$ & $<200^{\circ} \mathrm{C}$ & $<200^{\circ} \mathrm{C}$ & $<200^{\circ} \mathrm{C}$ & CA. $200^{\circ} \mathrm{C}$ \\
PRESSURE & $1.2 \times 10^{-2} \mathrm{MBAR}$ & $5 \times 10^{-3} \mathrm{MBAR}$ & $5 \times 10^{-3} \mathrm{MBAR}$ & $5 \times 10^{-3} \mathrm{MBAR}$ & $1.2 \times 10^{-2} \mathrm{MBAR}$ \\
\hline
\end{tabular}

stage of hybrid treatment consisted in tightening of the layer produced by using the hydrothermal type treatment. The treatment were produced simply by maintaining in a boiling aqueous bath for 15 to 120 min, similarly as is in the anodizing treatment [2].

In order for comparison, the layers on the AZ91D alloy were prepared which complied with consecutive stages of TiN2Ti1Al10 layer formation i.e. intermediate aluminium coating deposition at the first stage (A110), and transition titanium coating deposition at the second stage (Ti1A110).

Metallographic examination, X-ray diffraction analysis (XRD)—using a Siemens D500 spectrometer, and electron scanning microscopy (SEM)-Hitachi SU70 scanning microscope were the base for the microstructure characteristic.

The corrosion behavior of the AZ91D alloy, coated with the TiN2Ti1Al10 layer was examined in a 0.5M $\mathrm{NaCl}$ environment by the potentiodynamic and impedance (EIS) methods using an AutoLab PGSTAT 100 potentiostat. Impedance studies were carried out in a trielectrode system (tested electrode-reference electrode (SCE saturated calomel electrode)-auxiliary electrode (platinum)) in the frequency range of $10^{5}-10^{-3} \mathrm{~Hz}$, at a sine wave amplitude of $20 \mathrm{mV}$. The impedance spectra were analysed using Boukamp's EQUIVCRT program. The spectra obtained were presented in the form of a Bode plot. Potentiodynamic tests were carried out in the same trielectrode system. The samples were polarised with a potential change speed of $0.2 \mathrm{mV} / \mathrm{s}$.

\section{Results and Discussion}

Impedance measurement results, polarisation test results and data from the observation of the layers' surface immediately after depositing, tightening and after corrosion tests were the basis of the advanced analysis of corrosion behaviours of a TiN2Ti1Al10 titanium nitride composite layer and its constituent layers as well as the basis of the analysis of a substrate.

The impedance spectra of the AZ91D magnesium alloy are shown in Figures 2(a)-5(a) (in the form of a Bode plot) after the following surface modifications in the hybrid process, in accordance with Figure 1. The corresponding impedance spectra of the surfaces after hydrothermal tightening treatment are shown in Figures 2(b)-5(b). Characteristic electrochemical values obtained by impedance spectra analysis of magnesium AZ91D alloys with PVD layers, were given in Table 2. The surface topographies images are shown directly underneath the corresponding impedance spectra which are in Figure 2(c), Figure 2(d) and Figure 5(c), Figure 5(d). The results of polarisation tests are presented in Figure 6 and were given in Table 3.

In the case of the AZ91D magnesium alloy in the initial state (Figure 2(a)), a singular phase angle peak is 

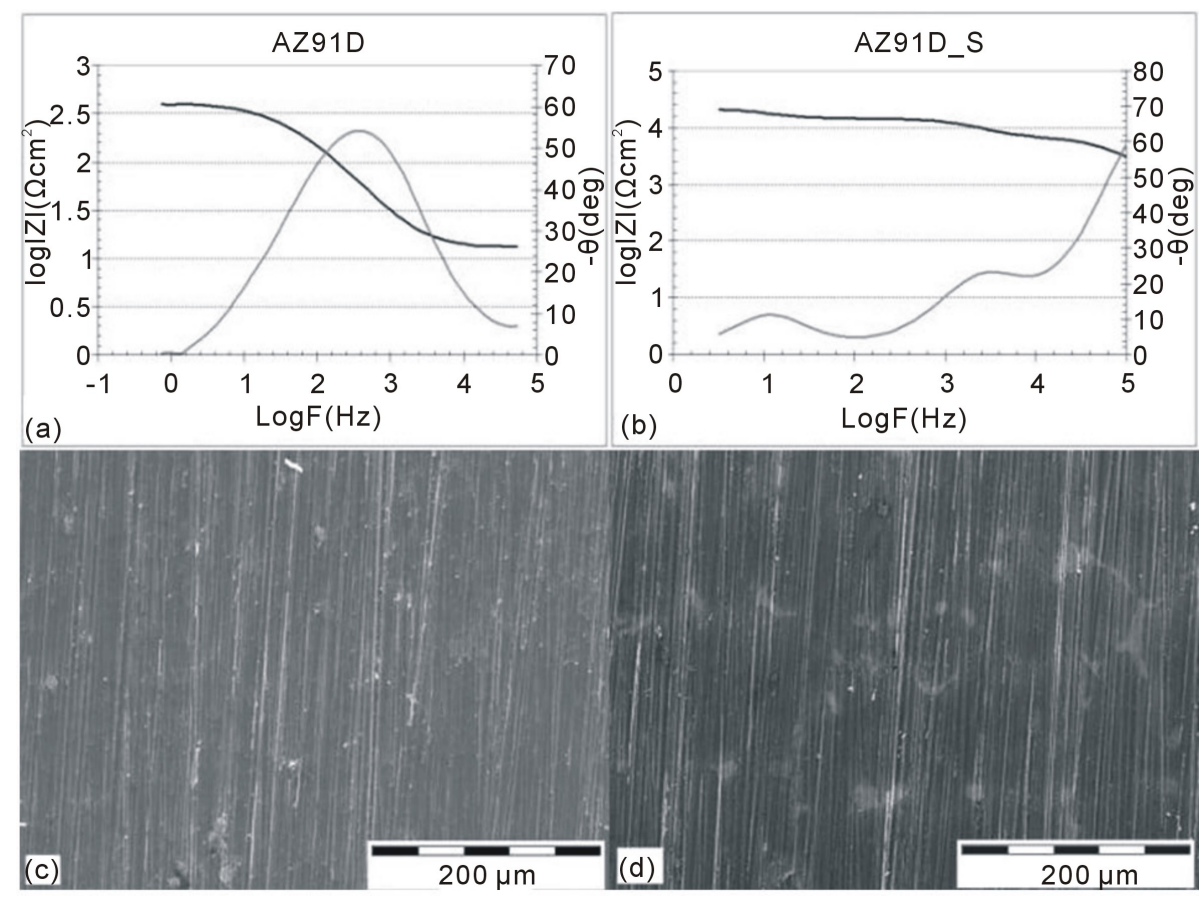

Figure 2. The impedance spectra of the AZ91D magnesium alloy at the initial state (AZ91D) (a) and after tightening process by means of a hydrothermal method (AZ91D S) (b) with the corresponding changes in the surface topography (c), (d).
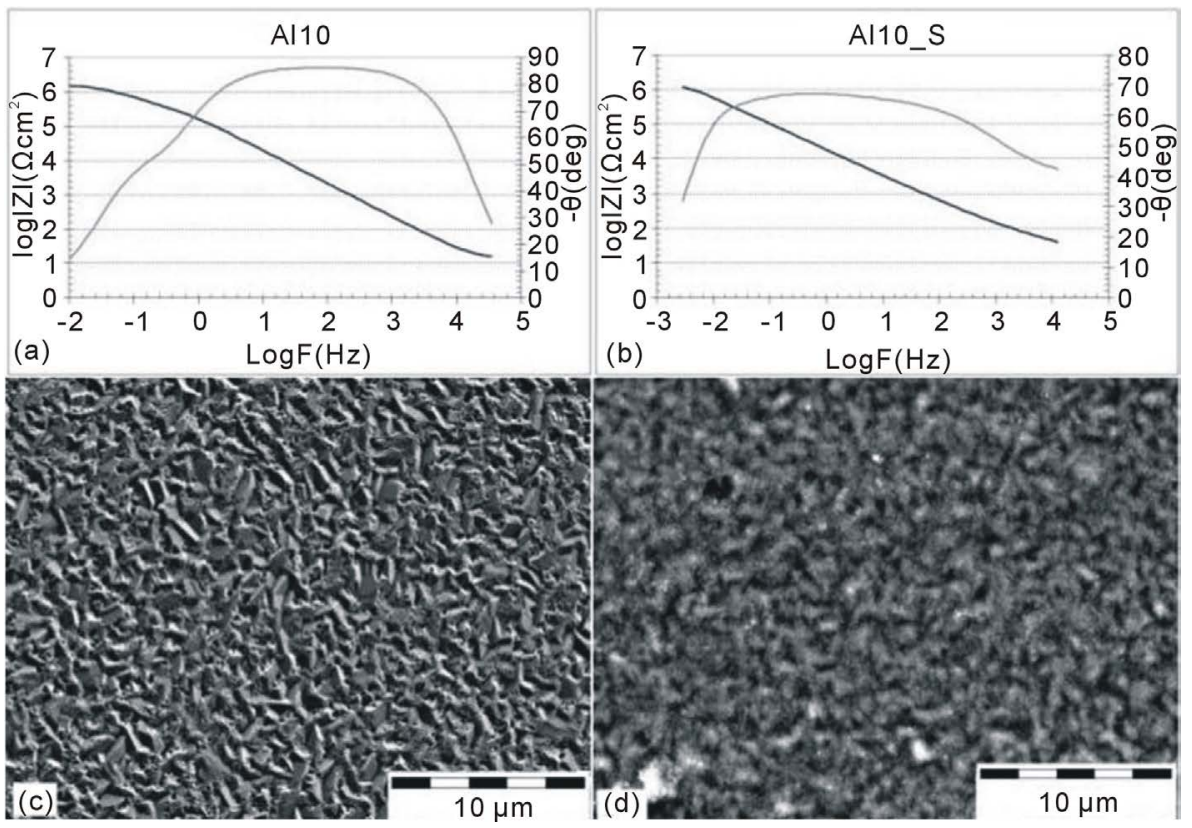

Figure 3. Impedance spectra of AZ91D magnesium alloy with a Al10 coating (a) and after the tightening with hydrothermal method (Al10_S) (b) with the corresponding surface topography (c), (d).

observed in the range of medium frequencies. The electrochemical parameters of this particular peak indicates the active substrate solubilises in the corrosive environment. The topography of the AZ91D alloy in the initial state is typical for the final mechanical treatment (with diamond polishing suspension) followed by a layer deposition in PVD processes (Figure 2(c)). Hydrothermal treatment of the AZ91D alloy results in a change in 

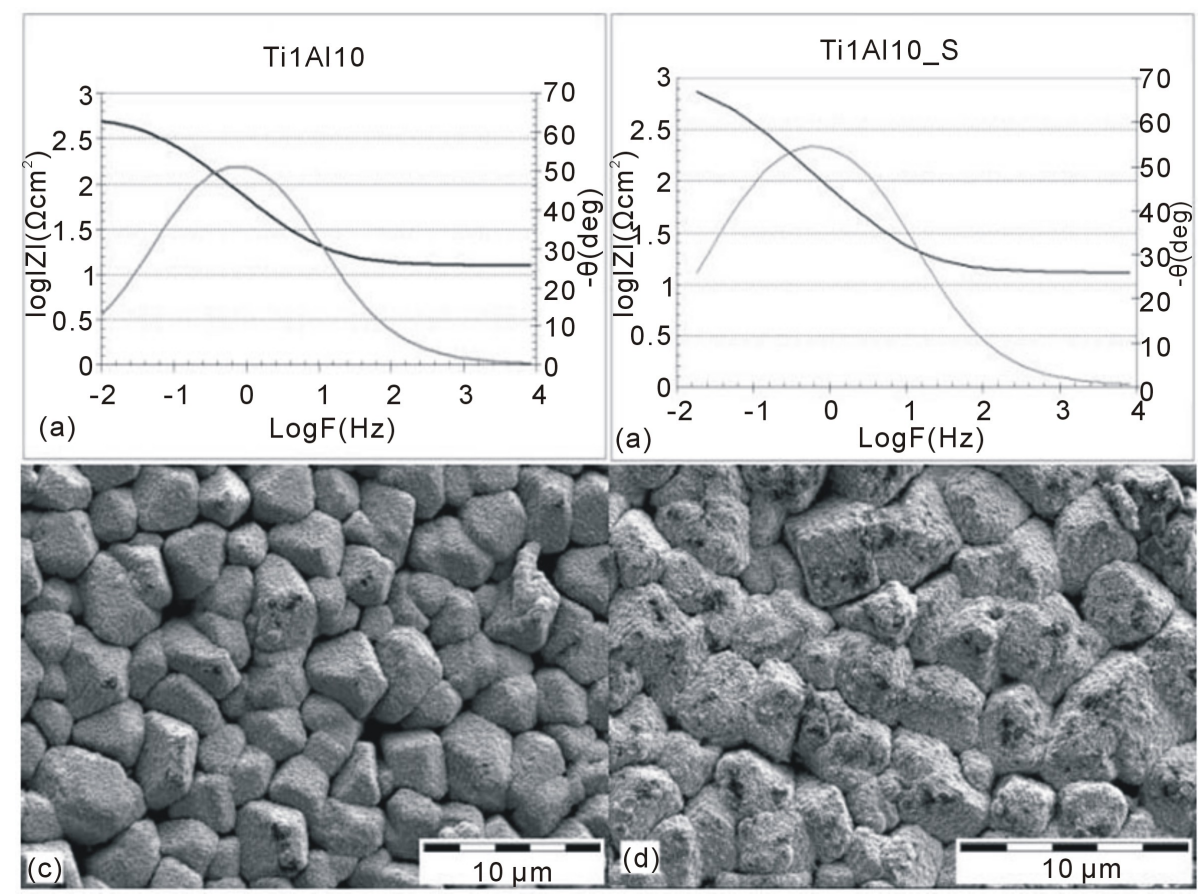

Figure 4. Impedance spectra of AZ91D magnesium alloy with a Ti1Al10 (a) coating (Ti1Al10) and after the tightening with hydrothermal method (Ti1Al10_S) (b) with the corresponding surface topography (c), (d).
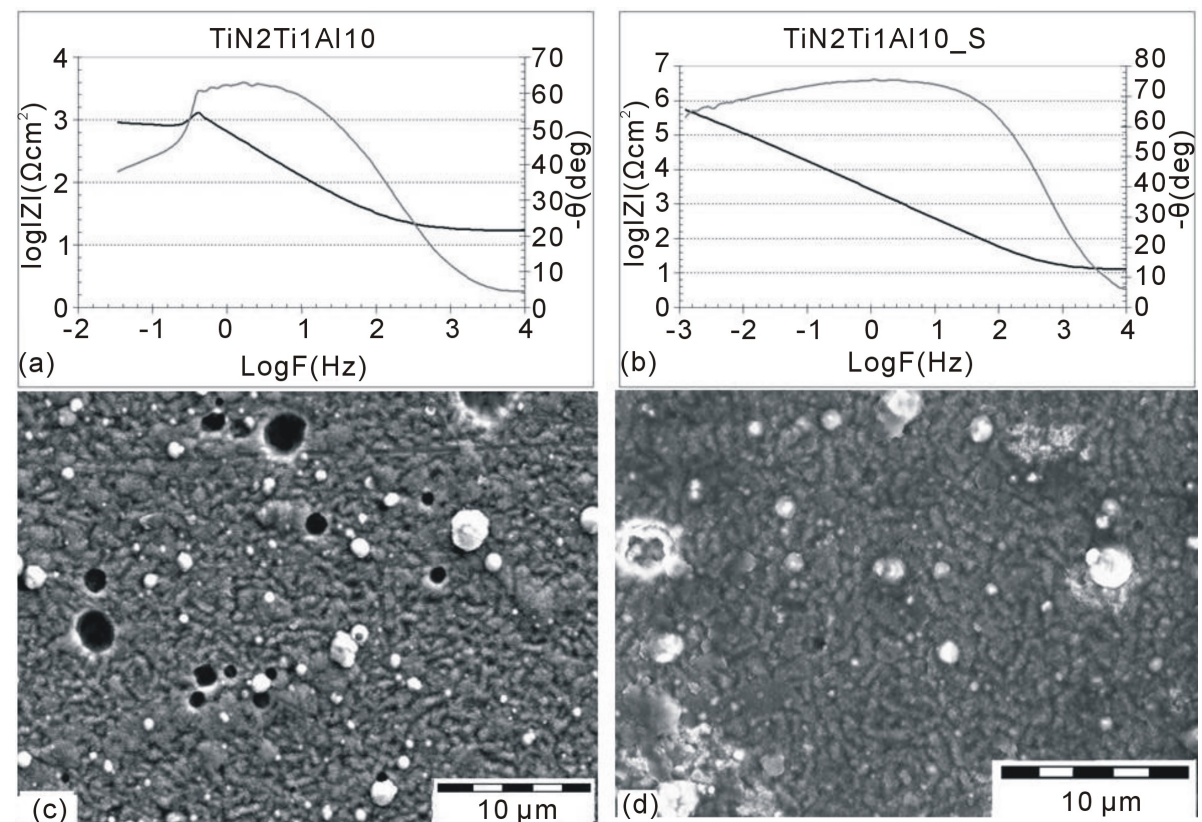

Figure 5. The impedance spectra of AZ91D alloy with a deposited TiN2Ti1Al10 coating (TiN2Ti1Al10) (a) and after the hydrothermal tightening process (TiN2Ti1Al10_S) (b) with the corresponding surface topography (c), (d).

the surface topography of the alloy (Figure 2(d)). This topography is characterised by the distinct local inhomogeneity of the surface appearance. This is undoubtedly associated with the structure of a passive layer being formed during hydrothermal treatment which is, in most likelihood, different for each phase constituting the structure of the AZ91D alloy (Mg ( $\mathrm{Al})$ solid solution and $\mathrm{Al}_{12} \mathrm{Mg}_{17}$ intermetallic phase). 


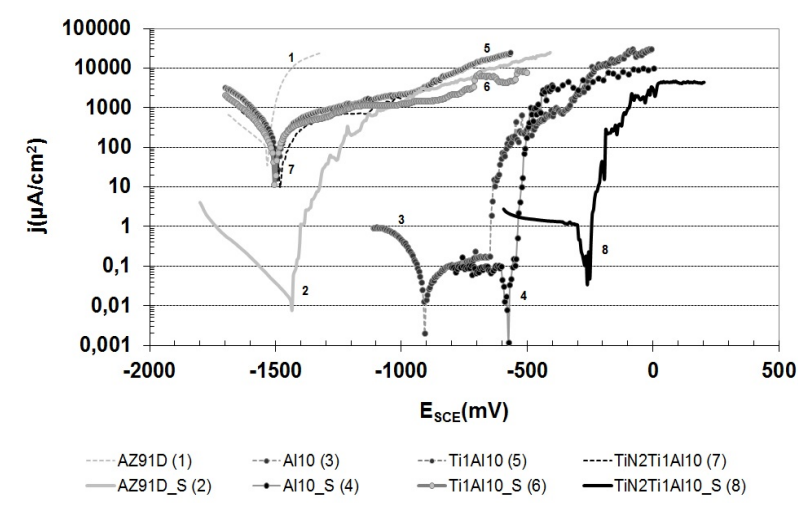

Figure 6. The polarisation curves of AZ91D magnesium alloy with the different surface layer produced with the use of hybrid method and after the tightening process by the hydrothermal method.

Table 2. The results of electrochemical impedance spectroscopy (EIS) tests.

\begin{tabular}{|c|c|c|c|c|}
\hline MATERIALS & PARAMETERS & $\mathrm{R} 1$ & $\mathrm{R} 2$ & $\mathrm{R} 3$ \\
\hline \multirow{3}{*}{ AZ91D } & $\mathrm{R}\left(\Omega \mathrm{cm}^{2}\right)$ & & & $3.8 \mathrm{E}+02$ \\
\hline & $\mathrm{Yo}_{\mathrm{CPE}}\left(\mathrm{F} \cdot \mathrm{cm}^{-2} \cdot \mathrm{s}^{\mathrm{n}-1}\right)$ & & & $3.2 \mathrm{E}-05$ \\
\hline & $\mathrm{n}$ & & & 0.81 \\
\hline \multirow{3}{*}{ AZ91D_S } & $\mathrm{R}\left(\Omega \mathrm{cm}^{2}\right)$ & $6.6 \mathrm{E}+03$ & $7.9 \mathrm{E}+03$ & $7.0 \mathrm{E}+03$ \\
\hline & $\mathrm{Yo}_{\mathrm{CPE}}\left(\mathrm{F} \cdot \mathrm{cm}^{-2} \cdot \mathrm{s}^{\mathrm{n}-1}\right)$ & $1.4 \mathrm{E}-09$ & $2.6 \mathrm{E}-08$ & $2.4 \mathrm{E}-06$ \\
\hline & $\mathrm{n}$ & 0.91 & 0.92 & 1 \\
\hline \multirow{3}{*}{ Al10 } & $\mathrm{R}\left(\Omega \mathrm{cm}^{2}\right)$ & & $5.3 \mathrm{E}+05$ & $1.2 \mathrm{E}+06$ \\
\hline & $\mathrm{Yo}_{\mathrm{CPE}}\left(\mathrm{F} \cdot \mathrm{cm}^{-2} \cdot \mathrm{s}^{\mathrm{n}-1}\right)$ & & $9.0 \mathrm{E}-07$ & $2.2 \mathrm{E}-06$ \\
\hline & $\mathrm{n}$ & & 0.96 & 0.88 \\
\hline \multirow{3}{*}{ Al10_S } & $\mathrm{R}\left(\Omega \mathrm{cm}^{2}\right)$ & $4.8 \mathrm{E}+01$ & $3.0 \mathrm{E}+05$ & $1.2 \mathrm{E}+06$ \\
\hline & $\mathrm{Yo}_{\mathrm{CPE}}\left(\mathrm{F} \cdot \mathrm{Cm}^{-2} \cdot \mathrm{s}^{\mathrm{n}-1}\right)$ & $1.0 \mathrm{E}-04$ & $1.8 \mathrm{E}-05$ & $3.6 \mathrm{E}-05$ \\
\hline & $\mathrm{n}$ & 0.48 & 0.7 & 1 \\
\hline \multirow{3}{*}{ Ti1Al10 } & $\mathrm{R}\left(\Omega \mathrm{cm}^{2}\right)$ & & & $5.8 \mathrm{E}+02$ \\
\hline & $\mathrm{Yo}_{\mathrm{CPE}}\left(\mathrm{F} \cdot \mathrm{cm}^{-2} \cdot \mathrm{s}^{\mathrm{n}-1}\right)$ & & & $3.8 \mathrm{E}-03$ \\
\hline & $\mathrm{n}$ & & & 0.72 \\
\hline \multirow{3}{*}{ Ti1Al10_S } & $\mathrm{R}\left(\Omega \mathrm{cm}^{2}\right)$ & & & $1.2 \mathrm{E}+03$ \\
\hline & $\mathrm{Yo}_{\mathrm{CPE}}\left(\mathrm{F} \cdot \mathrm{cm}^{-2} \cdot \mathrm{s}^{\mathrm{n}-1}\right)$ & & & $3.4 \mathrm{E}-03$ \\
\hline & $\mathrm{n}$ & & & 0.72 \\
\hline \multirow{3}{*}{ TiN2Ti1Al10 } & $\mathrm{R}\left(\Omega \mathrm{cm}^{2}\right)$ & & & $1.0 \mathrm{E}+04$ \\
\hline & $\mathrm{Yo}_{\mathrm{CPE}}\left(\mathrm{F} \cdot \mathrm{cm}^{-2} \cdot \mathrm{s}^{\mathrm{n}-1}\right)$ & & & $3.8 \mathrm{E}-04$ \\
\hline & $\mathrm{n}$ & & & 0.73 \\
\hline \multirow{3}{*}{ TiN2Ti1Al10_S } & $\mathrm{R}\left(\Omega \mathrm{cm}^{2}\right)$ & & $1.9 \mathrm{E}+04$ & $3.0 \mathrm{E}+06$ \\
\hline & $\mathrm{Yo}_{\mathrm{CPE}}\left(\mathrm{F} \cdot \mathrm{cm}^{-2} \cdot \mathrm{s}^{\mathrm{n}-1}\right)$ & & $5.2 \mathrm{E}-02$ & $9.6 \mathrm{E}^{-}-05$ \\
\hline & $\mathrm{n}$ & & 0.89 & 0.82 \\
\hline
\end{tabular}

A surface tightening process conducted by hydrothermal treatment can significantly modify corrosion resistance of the material. The presence of at least three phase angle peaks (Figure 2(b)) indicates the complexity of electrochemical processes occurring on the surface of the material. High values of the phase angle in the range of high frequencies and, simultaneously, high values of the resistance $\mathrm{R}_{\mathrm{S}}$ which are observed, indicate that there 
Table 3. The results of potentiodynamic corrosion tests.

\begin{tabular}{ccc}
\hline & $\mathrm{I}_{\text {cor }}\left(\mu \mathrm{A} \cdot \mathrm{cm}^{-2}\right)$ & $\mathrm{E}_{\text {cor }}(\mathrm{mV})$ \\
\hline AZ91D & 92 & -1530 \\
AZ91D_S & 0.015 & -1430 \\
Al10 & 0.04 & -900 \\
Al10_S & 0.07 & -570 \\
Ti1Al10 & 75 & -1500 \\
Ti1Al10_S & 75 & -1500 \\
TiN2Ti1Al10 & 50 & -1480 \\
TiN2Ti1Al10_S & 0.9 & -270 \\
\hline
\end{tabular}

is a thick ceramic layer present on the surface of the material. However, the presence of two additional peaks in the range of low frequencies indicates the segregation of the oxide layer and the occurrence of the corrosion processes. It may be assumed, according to SEM images (Figure 2(d)), that these additional peaks determine the oxide layer being formed on the surface of the $\mathrm{Al}_{12} \mathrm{Mg}_{17}$ intermetallic phase. Significant differences observed in the electrochemical parameters' values of the analysed peaks indicate that the constituent phases of the AZ91D alloy (Al12Mg17 i $\mathrm{Mg}(\mathrm{Al})$ are susceptible to passivation by using a hydrothermal method to a significantly various degree. This results in the increased electrochemical inhomogeneity of a substrate and in the formation of the corrosion microcells in the surface layer area. This, in turn, has an impact on the local decrease in the corrosion resistance of the dual phase material. The local substrate dissolutions of the AZ19D alloy are the effect of the varied electrochemical activity of a substrate component. They may be observed (Figure 7(a)) during the potentiodynamic tests.

In spite of the heterogeneity of the oxide layer which was observed, the process applied to modify the surface increased the corrosion resistance of the material in a significant way. It demonstrates that through both increasing the value of the resistance Rt (from $380 \Omega \mathrm{cm}^{2}$ to $7000 \Omega \mathrm{cm}^{2}$ ), and through the change in the substrate nature, the parameter " $n$ " increases towards more capacitive direction; (from $n=0.8$ to $n=0.99$ ).

The magnetron sputtering process applied during the first stage of the hybrid method enabled the formation of an aluminium coating with a thickness of approximately $10 \mu \mathrm{m}$ on the AZ91D alloy. The corresponding impedance spectra are shown on Figure 3(a), whereas the spectra of the alloy after the tightening process are presented on Figure 3(b). The surface topography of the aluminium coating before and after the tightening process is shown on Figure 3(c), Figure 3(d).

While analysing the plots presented, at least two (Al10) or three (Al10_S) time constants may be observed. They indicate the complexity of the electrochemical processes which occur on the surface of the layers. In the case of the aluminium coating on the AZ91D alloy in the as-deposited state (Al10) used in the analysis of the obtained impedance spectra, the equivalent circuit $\mathrm{R}(\mathrm{Q}[\mathrm{R}(\mathrm{RQ})])$ was used. It was typical for these materials which corrode locally. A dominant capacitive peak was observed in the wide range of frequencies $\left(10^{1} \mathrm{~Hz}-10^{4}\right.$ $\mathrm{Hz}$ ), and was characteristic for a passive layer $\left(\mathrm{Al}_{2} \mathrm{O}_{3}\right)$ created during the magnetron sputtering process; whereas the additional phase angle peak, which occurs at $10^{-1} \mathrm{~Hz}$ frequency, describes the electrochemical conditions in discontinuities of the oxide layer observed on the SEM images. It may be assumed that the defects of the layer are the initiation points for the pitting corrosion. It may be confirmed by the " $n$ " parameter of the analysed peak (approximately, $n=0.8$ ). It indicates the points of high electrochemical activity, typical for the areas subjected to the active pulping.

The tightening process applied on the layer slightly modified the quality of the electrochemical processes occurring on the surface of the material. However, it did not cause any significant change in the corrosion resistance of the material (the resistance-Rt was around $1.2 \times 10^{6} \Omega \mathrm{cm}^{2}$ in both cases). The presence of a dominant peak in the wide frequency range indicates that the material is in the passive state. Nevertheless, the presence of two additional peaks occurring at high frequencies and, simultaneously, their strong coincidence with the dominant capacitive peak, indicates two independent electrochemical processes of small intensity. Based on the analysis of the electrochemical values of the loops (low resistance, " $n$ " parameter indicating the diffusive-active conditions in the layer) and on the SEM images, it may be assumed that the analysed peaks describe the conditions which take place in the infrequent discontinuities of a layer (Figure 3(d)) and the conditions of the aluminium oxide or the magnesium formation in such discontinuities. It may be confirmed by the corrosion poten- 

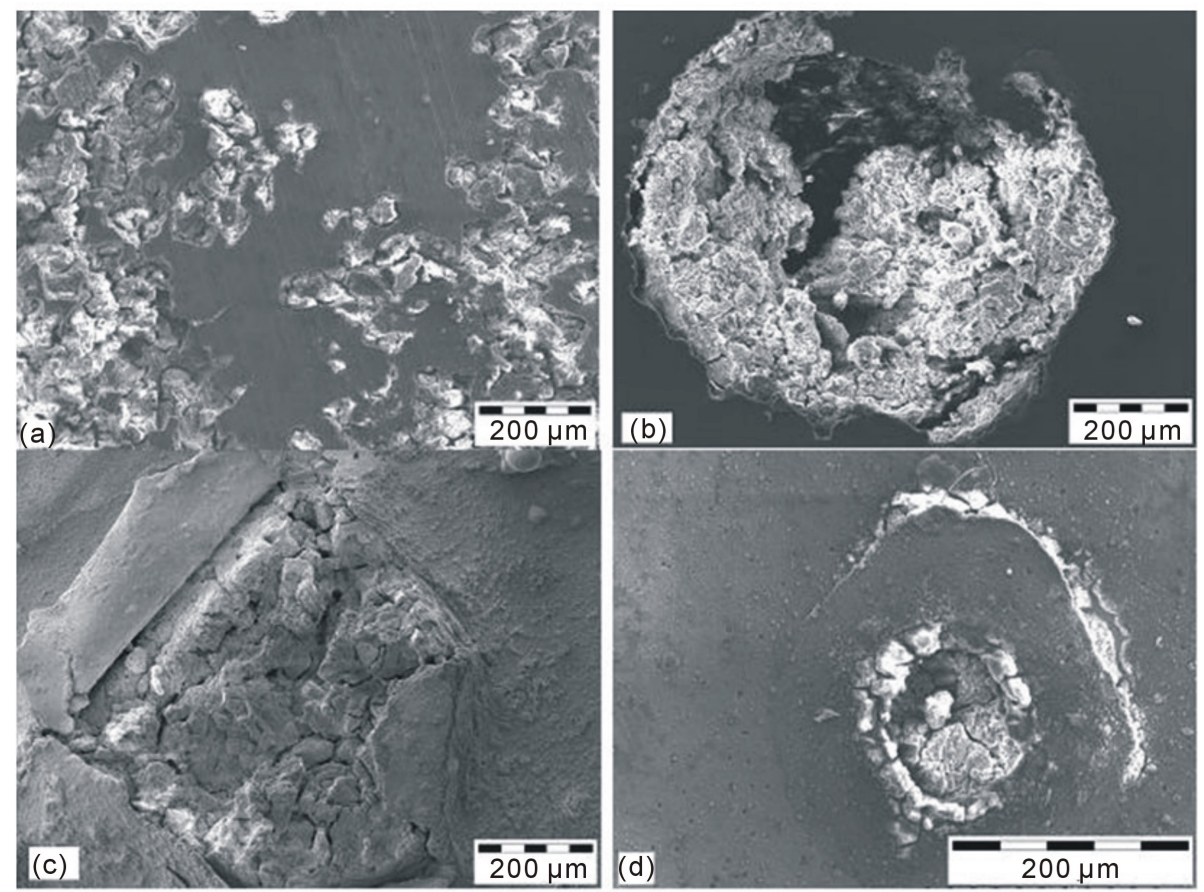

Figure 7. Corrosion damages of the examined coatings after the potentiodynamic tests. (a) AZ91D_S; (b) Al10_S; (c) Ti1Al10_S; (d) TiN2Ti1Al10_S.

tial which was slightly decreased in comparison with pure aluminium and significantly higher in relation to pure magnesium.

At the next stage of the hybrid technology of the TiN2Ti1Al10 layer production (on the AZ91D magnesium alloy with the aluminium coating), a titanium coating was deposited with the use of the magnetron sputtering method. Thus, the Ti1Al10 type coating was obtained. Its impedance spectra are shown on Figure 4(a). The spectra of the coating after the tightening process are presented on Figure 4(b), whereas the topography of the layer, before and after the tightening process is shown on Figure 4(c), Figure 4(d).

The analysis of the impedance spectra (Figure 4(a)) indicates that the produced layer significantly decreases the corrosion resistance of the aluminium coating produced on the AZ91D alloy. It becomes apparent through the significant decrease in the values of the resistance Rt (from $1.2 \times 10^{6} \Omega \mathrm{cm}^{2}$ to $580 \Omega \mathrm{cm}^{2}$ ), as well as through the change in the substrate nature that the material becomes active and electrochemically corrodes in a very intensive way. It may be assumed that the structure of a titanium layer is responsible for the obtained results (Figure 4(d)). Within this structure, the regular crystallites separated from each other, are observed. They enable the electrolyte to fully penetrate the layer, and they also allow the active pulping of a substrate. Such interpretation may be supported by the corrosion potential of a layer $(-1450 \mathrm{mV})$ which is similar to the corrosion potential of magnesium. The tightening process only slightly increased the corrosion resistance of a layer but it did not change the form of the impedance spectrum. The topography of a Ti1Al10 layer after the tightening process (Figure 4(d)) indicates that the oxide layers only partly homogenised a titanium substrate. Nevertheless, it did not insulate all the porosities of the layer. The evidence of this may also lie in the corrosion potential of the material which only increased slightly (approx. $-1350 \mathrm{mV}$ ) in comparison to the titanium layer obtained after the magnetron treatment.

Considering the values of the normal potential of the $\mathrm{Al} / \mathrm{Al}^{3+}$ electrode of first kind equal to $\mathrm{E}_{0}=-1.662 \mathrm{~V}$ and close to the values obtained in this study, it may be assumed that the passive aluminium oxides layer $\left(\mathrm{Al}_{2} \mathrm{O}_{3}\right)$, which would increase corrosion resistance of the composite, does not recreate in the discontinuities of titanium layer (on the titanium/aluminium interface). Instead, active substrate dissolution occurs. One of the reasons for this may lie in the concentration of the chloride ions being increased in the pinholes of the layer which decreases $\mathrm{pH}$ of solution, and this, in turn, disenables the spontaneous recreation of the passive aluminium layer. The galvanic corrosion of the metals which constitute the composite layer may also be one of the 
possible explanations. Moreover, the ongoing chemical tightening process occurring within the titanium coating, does not improve corrosion resistance in any significant way. This is due to the specific structure of the coating which limits its tightness along with the hampering of the aluminium coating passivation process.

In the light of the results' analysis presented above, it should be assumed that the system composed of aluminium and titanium intermediate coatings does not tighten the examined TiN2Ti1Al10 composite layer. Moreover, it can be concluded that the tightening of this layer occurs in the outside titanium nitride layer. Initial results of further complementary studies clearly indicate that the presence of the intermediate aluminium coating in the layer structure is crucial in terms of the effectiveness of the tightening process of the outside titanium nitride layer. While the presence of a titanium nitride sub-layer is important to obtain the desired gradient of mechanical properties and to produce the diffusion bonding between the sub-layers.

The next (third) stage of the hybrid technology used for creating the TiN2Ti1Al10 composite layer on magnesium alloy (Figure 1) consisted of depositing the top titanium nitride coating onto the double intermediate Ti1Al10 layer by means of the arc evaporation method. The impedance spectra of a composite layer are shown on Figure 5(a), and a layer after the tightening process on Figure 5(b). The topography before and after the tightening process is presented on Figure 5(c), Figure 5(d).

The TiN outside layer, which forms during this process, overbuilts the discontinuities in the titanium sublayer to a significant extent [14] thus electrochemically homogenising the surface and decreasing its roughness (Figure 5(a)). However, it did not cause any significant increase in the corrosion resistance of the substrate. Additionally, a decrease in the value of the impedance module in the range of low frequencies, observed during the impedance measurements may indicate a substrate degradation during the exposure. The structure of the layer (Figure 5(c)) affected the obtained result due to the frequent pinholes which decrease its durability.

The tightening process by hydrothermal treatment applied in the present study significantly increased the corrosion resistance of the layer. This becomes apparent through increasing both the value of the resistance Rt (3.0 $\left.\times 10^{6} \Omega \mathrm{cm}^{2}\right)$ and the nobility of the substrate with a layer (the corrosion potential of a filled sample equals about $-270 \mathrm{mV}$ ). However, the analysis of the impedance spectra shown on Figure 5(b) indicates the presence of two peaks depicting the electrochemical segregation of the surface. A dominant capacitive peak, which occurs in the wide frequency range (from $10^{-1} \mathrm{~Hz}$ to $10^{2} \mathrm{~Hz}$ ), indicates the presence of the passive top layer (presumably oxide layer). However, the extra peak (its " $\mathrm{n}$ " parameter equal to 0.82 ) reveals the areas of increased electrochemical activity which may become the initiation points for the pitting corrosion. Thus, due to lack of the tightening influence of the presence of the of Ti1Al10 type intermediate layers system in the of TiN2Ti1Al10 layer structure, it may be assumed that the covering of its surface with a passive, ceramic (oxide) coating (Figure 5(d)), is the controlling factor in the improvement of the electrochemical properties of the layer using a final hydrothermal treatment.

The results of the potentiodynamic test, shown on Figure 6, reveal that the produced layers have a diverse influence on the change of the corrosion resistance of AZ91D magnesium alloy. In most cases (AZ91D, Ti1Al10, TiN2Ti1Al10), the corrosion resistance changes minimally due to the inhomogenity of the layers and due to numerous structure defects (Figures 3(c)-5(c)). This is observed due to the similar values of the corrosion potentials and the comparable density values of the corrosive currents. Only when tight aluminium layers are produced with the use of the magnetron method (Al10), a significant increase in the corrosion resistance of a substrate may be observed. It is revealed through a decrease in the rate of corrosion of 4 orders of magnitude and also as a significant shift of the corrosion potentials (of approx., $+700 \mathrm{mV}$ ) towards the anodic side. Additionally, Al10 layers in $0.5 \mathrm{M} \mathrm{NaCl}$ environment are in the passive state in a wide range of potentials and after exceeding the pitting potential, it undergoes the pitting corrosion.

Extremely different results regarding the corrosion resistance of the AZ91D magnesium alloy could be observed when the surfaces of the substrate and the examined layers were additionally tightening using with the hydrothermal method. In most of the cases (except Ti1Al10_S layer), an increase in the corrosion resistance of the analysed layers may be observed. However, due to the chemical composition of the surface layer, the tightening effect on the changes in the corrosion resistance of the adequate substrate is diverse. Table 3 shows the results of potentiodynamic corrosion test of PVD layers which were tightened as compared to the initial material.

Through the analysis of the data presented in Table 3, it was revealed that the tightening process improves the corrosion resistance of the aluminium coating (A110). This can be efficiently achieved by using the hydrothermal method, most probably, through covering the coating surface with aluminium oxide. Regarding the titanium 
oxides, which occur in the Ti1Al10 layer, their discontinuous structure (Figure 4(c)) brings unsatisfactory results in terms of tightening efficiency of the layer. Producing a titanium layer of a different, more homogenous structure would probably result in a significant increase in the corrosion resistance after the filling process. Especially, when the comparable chemical affinity of titanium and aluminium to oxygen and the formation of $\mathrm{Al}_{2} \mathrm{O}_{3}$ and $\mathrm{TiO}_{2}$ oxides are taken into account. Significant changes in the values of the electrochemical parameters of the TiN2Ti1Al10 layer after the tightening process and with the specific form of the potentiodynamic curves in the cathode area, which is characteristic for the processes remaining under diffusive control, indicate that the TiN2Ti1Al10 layer is chemically neutral. Durability of the layer, observed in the cathode area and the significant changes in the corrosion potential values towards more positive ones, may be partly caused by dissolution of the most active inclusions during the electroless exposure of a substrate. It may also result from the process of filling numerous pinholes and defects in the nitride layer which may be observed after the arc process. However, due to the cathode nature of a layer, the local areas with limited durability which occur in the layer (pinholes not fully filled), are conducive to the breakdown and to the initiation of the pitting corrosion.

The observation of a surface after corrosion tests (Figure 7) indicates that both the substrate subjected to the tightening treatment (Figure 7(a)) and all the examined variants of the layers (Figures 7(b)-(d)) corrode locally with various intensity. With regard to the Ti1A110 coating (Figures 7(c)), the potentiodynamic curves shown on Figure 6 indicate general corrosion. Such a result seems inconsistent with the types of corrosion damage shown in Figure 7 which indicates the pitting corrosion of a surface. The cause of these inconsistencies lies in the significant number of pitting initiation points which renders the entire examined surface vulnerable. In terms of the cathodic coatings Al10 and TiN2Ti1Al10 (Figures 7(b)-(d)), corrosion damages are typical for the chemically neutral cathodic coatings after the breakdown of a layer occurring as a result of the anodic polarisation in the very active environment $(0.5 \mathrm{M} \mathrm{NaCl})$. In the light of these results, in order to obtain the maximum effectiveness of the tightening treatment its optimisation would be required in the future.

\section{Conclusions}

Detailed research, regarding the corrosion resistance of the composite titanium nitride TiN-Ti-Al type layer on the titanium aluminium sub-layer produced on AZ91D alloy in hybrid process that combine deposition PVD with final tightening, characterised by complex electrochemical structure, were carried out. Thanks to the impedance spectroscopy, such research enabled in-depth assessment of corrosion behaviours of the composite layer and its constituent aluminium and titanium sub-layers. In particular, it allowed the effect of the tightening treatment conducted with a hydrothermal method on the quality of the constituent sub-layers to be determined. The impedance measurements were the base for the diagnosis of the type, the amount and the intensity of particular electrochemical processes which occur on the surface of the composite layer and sub-layers, exposed in $0.5 \mathrm{M} \mathrm{NaCl}$. By this means, the electrochemical durability of the layers was determined at subsequent stages of the formation of a composite layer in hybrid process as well as the contribution of the constituent sub-layers to the effect of significant increase in the corrosion resistance obtained by the hydrothermal method.

1) The increase in the impedance values (about $\Delta \mathrm{Rt}=1 \times 10^{6} \Omega \mathrm{cm}^{2}$ ), distinct growth in the corrosion potential $(\Delta \mathrm{E}=350 \mathrm{mV})$, and the nature of the impedance spectra indicate that the tightening process using the hydrothermal method significantly increases the corrosion resistance of the aluminium coating on the AZ91D alloy deposited in the first stage of hybrid process aimed to produce a composite TiN-Ti-Al type layer. This originated from the formation on its surface of a tight coating of ceramic kind, which is probably an oxide one of $\mathrm{Al}_{2} \mathrm{O}_{3}$ type.

2) Covering the AZ91D alloy with aluminium and titanium coatings constituting the Ti-Al type sub-layers system in the structure of the composite TiN-Ti-Al, in consecutive two stages of a hybrid process, results in a decrease of electrochemical properties to the level approximate to the untreated alloy $\left(\mathrm{Rt}=380 \Omega \mathrm{cm}^{2}\right.$, Ecor $=$ $-1500 \mathrm{mV}$ ). Such an effect is, in all likelihood, the result of the formation of corrosion cells between the intermediate titanium and aluminium coatings, Moreover, due to the specific structure of the titanium sub-layer which limits the tightness, the hydrothermal tightening process does not improve corrosion resistance of the Ti-Al sub-layers system. Therefore, the titanium and aluminium sub-layers system does not tighten the examined TiN-Ti-Al composite layer. This indicates that the tightening by using hydrothermal method occurs in the outside titanium nitride layer. However, as it is clearly indicated by the results of further complementary studies, the presence of both aluminium and titanium sub-layers in the composite TiN-Ti-Al layer structure is indispen- 
sable from the perspective of the final properties of the layer. The presence of aluminium sub-layer is crucial to enable the effective tightening treatment of the outside titanium nitride layer. The presence of the titanium sub-layer is important due to the expected gradient of mechanical properties.

3) The as deposited composite TiN-Ti-Al type titanium nitride layer on titanium and aluminium sub-layer produced on the AZ91D magnesium alloy in third stage of hybrid process does not improve corrosion resistance. This is due to the porous and defected structure of the outside titanium nitride layer typical of the arc evaporation method applied for its deposition combined with the lack of tightening effect of the intermediate coatings titanium and aluminium system.

4) The tightening process using hydrothermal method applied in the final stage of hybrid process increases the corrosion resistance of the composite TiN-Ti-Al layer in a significant way. As a result, high electrochemical parameters can be achieved, i.e. the impedance $\left(\mathrm{Rt}=3.0 \times 10^{6} \Omega \mathrm{cm}^{2}\right)$, and the chemical activity $(\Delta \mathrm{E}=1300 \mathrm{mV})$ can be reduced. During the impedance measurements, the layer displayed behaviours typical for the tight ceramic layers which may suggest that covering titanium nitride surface and all the defects present on it with a titanium oxide coating would be the effect of the hydrothermal treatment. Covering the surface of TiN-Ti-Al layer with the passive oxide coating is the effect that controls the increase in electrochemical parameters of a layer through the final hydrothermal treatment. The quality of the tightening is essential for the durability of a layer due to the cathode nature of a composite layer, on magnesium AZ91D alloy, and due to the pitting corrosion mechanism. Hence, it would be reasonable to undertake the optimization of the tightening treatment in order to obtain maximal effectiveness.

\section{References}

[1] Gray, J.E. and Luan, B. (2002) Protective Coatings on Magnesium and Its Alloys-A Critical Review. Journal of Alloys and Compounds, 336, 88-113. http://dx.doi.org/10.1016/S0925-8388(01)01899-0

[2] Hoche, H., Schroeder, H.-J., Scheerer, H., Broszeit, E. and Berger, C. (2002) Tribological Studies of CrN Coated Magnesium AZ91 at Temperatures up to 250. Advanced Engineering Materials, 4, $42-51$. http://dx.doi.org/10.1002/1527-2648(20020212)4:1/2<42::AID-ADEM42>3.0.CO;2-E

[3] Hollstein, F., Wiedemann, R. and Scholz, J. (2003) Characteristics of PVD-Coatings on AZ31hp Magnesium Alloys. Surface and Coatings Technology, 162, 261-268. http://dx.doi.org/10.1016/S0257-8972(02)00671-0

[4] Hoche, H., Blawert, C., Broszeit, E. and Berger, C. (2005) Galvanic Corrosion Properties of Differently PVD-Treated Magnesium Die Cast Alloy AZ91. Surface and Coatings Technology, 193, 223-229. http://dx.doi.org/10.1016/j.surfcoat.2004.08.147

[5] Altun, H. and Sen, S. (2005) The Effect of DC Magnetron Sputtering AlN Coatings on the Corrosion Behaviour of Magnesium Alloys. Surface and Coatings Technology, 197, 193-200. http://dx.doi.org/10.1016/j.surfcoat.2004.06.001

[6] Zhou, H., Chen, F., Yao, B., Han, G. and Jawid, A. (2007) Properties of the TiN Coatings on Previously Ti Ion-Implanted Magnesium Alloy Substrate. Surface and Coatings Technology, 201, 6730-6733. http://dx.doi.org/10.1016/j.surfcoat.2006.09.116

[7] Altun, H. and Sinci, H. (2008) Corrosion Behavior of Magnesium Alloys Coated with TiN by Cathodic Arc Deposition in NaCl and Na2SO4 Solutions. Mater Character, 59, 266-270. http://dx.doi.org/10.1016/j.matchar.2007.01.004

[8] Tacikowski, M., Rudnicki, J., Walkowicz, J. and Wierzchoń, T. (2009) Structure and Properties of Composite Layers on AZ91D Magnesium Alloy Produced by the Hybrid Surface Treatment. NETSU-SHORI. Journal of The Japan Society for Heat Treatment, 49, 365-368.

[9] Tacikowski, M., Kamiński, J., Rudnicki, J., Borowski, T., Trzaska, M. and Wierzchoń, T. (2009) The Effect of the Diffusive, Composite Chromium Nitride Layers Produced by a Hybrid Surface Treatment on the Corrosion Behavior of AZ91D Magnesium Alloy. Vacuum, 85, 938-942. http://dx.doi.org/10.1016/j.vacuum.2011.01.016

[10] Tacikowski, M. and Wierzchoń, T. (2011) Controlling of Corrosion Resistance of Magnesium Alloys Using Hybrid Method. Corrosion Protection, 2, 40-43.

[11] Hoche, H., Allebrandt, D., Scheerer, H. and Berger, C. (2007) Engineering and Design of Wear and Corrosion Resistant PVD Coatings Regarding the Exceptional Properties of Magnesium Substrates. Plasma Processes and Polymers, 4, 568-573. http://dx.doi.org/10.1002/ppap.200731407

[12] Fenker, M., Balzer, M. and Kappl, H. (2006) Corrosion Behavior of Decorative and Wear Resistant Coatings on Steel Deposited by Reactive Magnetron Sputtering-Tests and Improvements. Thin Solid Films, 515, 27-32. http://dx.doi.org/10.1016/j.tsf.2005.12.020

[13] Tacikowski, M. (2012) Patent Application No. P-401207, Poland. 
[14] Tacikowski, M., Banaszek, M. and Smolik, J. (2014) Corrosion-Resistant Composite Titanium Nitride Layers Produced on the AZ91D Magnesium Alloy by a Hybrid Method. Vacuum, 99, 298-302.

http://dx.doi.org/10.1016/j.vacuum.2013.06.018 
Scientific Research Publishing (SCIRP) is one of the largest Open Access journal publishers. It is currently publishing more than 200 open access, online, peer-reviewed journals covering a wide range of academic disciplines. SCIRP serves the worldwide academic communities and contributes to the progress and application of science with its publication.

Other selected journals from SCIRP are listed as below. Submit your manuscript to us via either submit@scirp.org or Online Submission Portal.
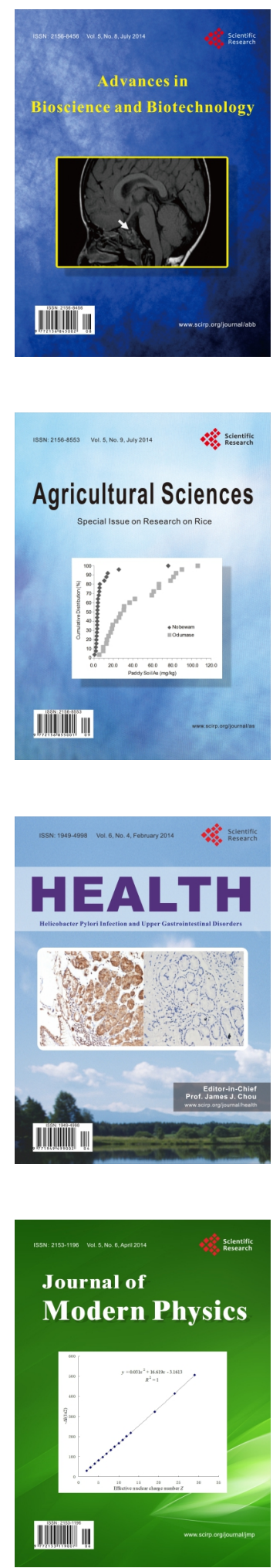
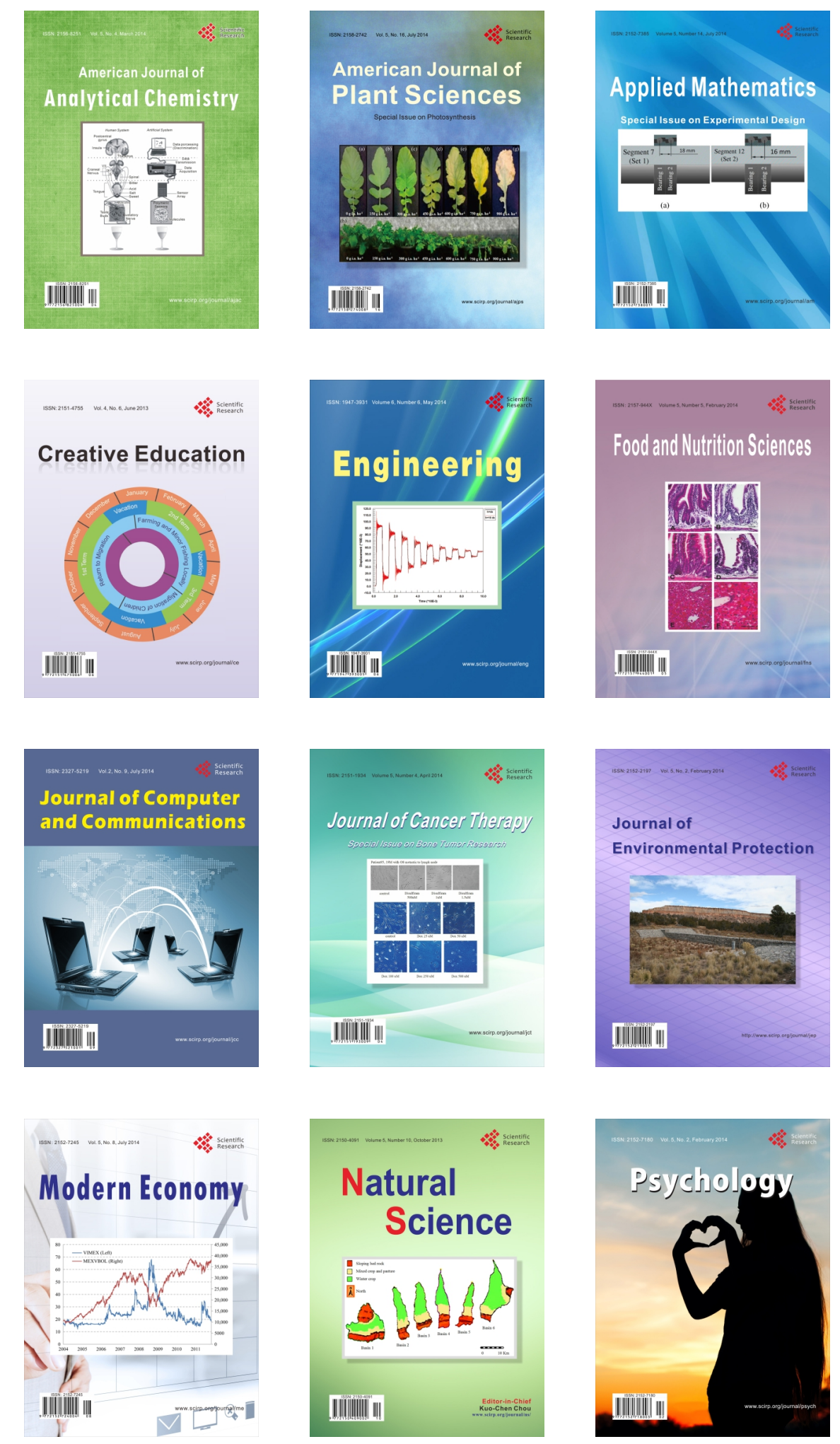